\title{
Multistakeholderism: anatomy of an inchoate global institution
}

\author{
MARK RAYMOND ${ }^{1}$ and LAURA DENARDIS ${ }^{2}$ \\ ${ }^{1}$ Wick Cary Assistant Professor of International Security, Department of International and Area Studies, \\ University of Oklahoma, Norman, OK, USA \\ ${ }^{2}$ School of Communication, American University, Washington, DC, USA
}

E-mail: mraymond@ou.edu,denardis@american.edu

Building on John Ruggie's pioneering study of multilateralism, this paper presents an analogous study of multistakeholder governance, or multistakeholderism. Its central argument is that multistakeholderism is, as yet, a much less well-defined institutional form. Cases exhibit significant variation both in the combinations of actor classes entitled to participate and the nature of authority relations among those actors. The first section discusses multistakeholderism as an institutional form, and proposes a taxonomy of its types. This section also briefly addresses the implications of the analysis for International Relations theory. The paper then conducts a comparative analysis of multistakeholderism, applying the taxonomy to five illustrative cases. It demonstrates the degree of inter-case variation, and the range of issue-areas across which the institutional form is employed and invoked by actors. Three cases are drawn from the increasingly contentious area of Internet governance; the paper thus makes a secondary contribution to this growing literature. The paper's most striking finding in this regard is that Internet governance often fails to live up to its multistakeholder rhetoric. Other cases include governance of securities regulation and the governance of corporate social responsibility. The paper concludes by examining the implications of our argument, and identifying areas for further research.

Keywords: multistakeholder governance; global governance; Internet governance; institutions; authority; rules

In 1992, John Ruggie published a seminal article on the institution of multilateralism in a special issue of the journal International Organization (Ruggie 1992). The Ruggie article and others in the special issue were not the first International Relations (IR) work on multilateralism. However, Ruggie's article, in particular, catalyzed the emergence of a literature studying the phenomenon across a range of issue areas, ${ }^{1}$ and was enormously

${ }^{1}$ See, for example, Drezner (2000) on the efficacy of multilateral economic sanctions; and Wilkinson (2000) on multilateralism and international trade regulation. 
influential in the development of literatures on global governance and the structure of the international system (Reus-Smit 1997; Ikenberry 2001). In the ensuing decades, multilateral diplomacy has remained both an important object of scholarly inquiry and an enduring international institution.

At the same time, new practices and discourses have emerged in response to the efforts of a range of non-state actors to participate more fully in the enterprise of governing the globe, whether or not in multilateral processes (see, e.g., Keck and Sikkink 1998; Price 1998; Weissbrodt and Kruger 2003; Glasius 2010). We argue that much of this activity can be understood by thinking in terms of a distinct, emerging (and as-yet inchoate) institution of multistakeholderism or multistakeholder governance. Influenced by Ruggie's work on multilateralism, our goal in this paper is to conduct a parallel analysis of multistakeholderism. Existing studies of multistakeholderism tend to be issue-specific, and concentrated in a small number of technical areas such as Internet governance (see, e.g., Antonova 2008, Malcolm 2008). Further, the concept remains underdeveloped and susceptible to use in attempts to conceal or advance particular interests or agendas. Our framing of multistakeholderism in juxtaposition with multilateralism highlights multistakeholderism as a broader phenomenon and facilitates comparative study. It also suggests (and speaks to the nature of) potential change in the fundamental institutions of the international system, sheds light on the existence of complex authority relations in that system, and connects the global governance literature to the literature on the international system.

We define multistakeholderism as two or more classes of actors engaged in a common governance enterprise concerning issues they regard as public in nature, and characterized by polyarchic authority relations constituted by procedural rules. We further disaggregate the concept of multistakeholderism into a typology that distinguishes several forms on the basis of the varieties of actors involved and the nature of authority relations between them. This typology reflects the existence of considerable variation among particular instantiations of the generic institutional form. In this sense, we suggest that the rules and practices structuring the institution remain in flux. It is for this reason that we refer to multistakeholderism as an inchoate global institution.

We apply our taxonomy to a comparative analysis of several examples of institutional arrangements sometimes considered multistakeholder. The first three cases address an area of global governance broadly recognized as increasingly contentious, and frequently described as multistakeholder global governance of the Internet. Accordingly, the article makes important secondary contributions to the growing Internet governance literature. In this regard we emphasize both that multistakeholderism is not unique to Internet governance and that not all Internet governance tasks and 
functions are accomplished via multistakeholder modalities. The fourth and fifth cases address global governance of securities trading by the International Organization of Securities Commissions (IOSCO) and governance of corporate social responsibility by the Global Compact (GC). Presentation of the cases is followed by analysis of the variation in actor classes and authority relations, which we argue are an important part the products of different sets of procedural rules that constitute (and therefore at least partially explain) (Wendt 1998) particular instances of multistakeholder governance, and that also distinguish multistakeholder from non-multistakeholder governance.

The article concludes by offering critiques of how multistakeholder models are applied both in theory and practice; and by raising questions for future research about the factors determining whether (and in what form) multistakeholderism is practiced in a particular issue area, the dynamics of multistakeholderism over time, and the appropriate criteria for matching governance modalities to particular governance functions. We also highlight potential gains from increased attention in IR theory to the study of procedural rules, which we argue can productively inform scholarship on institutional forms, and on the nature and extent of authority relations in the international system.

\section{Forms of multistakeholder governance}

In the most general terms, multistakeholderism entails two or more classes of actors engaged in a common governance enterprise concerning issues they regard as public in nature, and characterized by polyarchic authority relations constituted by procedural rules. Further, we argue that there are many possible types of multistakeholder governance, produced by variation on at least two dimensions: (1) the types of actors involved; and (2) the nature of authority relations between actors. In this section we develop the various elements of this definition and explicate a typology of forms of multistakeholderism.

In order to qualify as multistakeholder governance, we argue that at least two classes of actors must be involved. This condition is similar to what Ruggie called the nominal or thin definition of multilateralism proposed by Robert O. Keohane: 'the practice of coordinating national policies in groups of three or more states, through ad hoc arrangements or by means of institutions' (Keohane 1990, 731). Ruggie argued, persuasively, that such a thin definition of multilateralism 'misses the qualitative dimension of the phenomenon that makes it distinct' and that 'the issue is not the number of parties so much... as it is the kind of relations that are instituted among them' (Ruggie 1992, 566). Nevertheless, we believe that starting with the 
thin definition is appropriate for our purposes in this article because it leaves open the empirical question whether there is, in fact, a single distinctive kind of relations between actors typical of cases commonly described as multistakeholder.

Indeed, as our introduction suggests and as we will argue in further detail below, the available evidence shows that multistakeholder governance is (at least at present) a much less coherent institutional form than multilateralism. It is less coherent in the sense that the label multistakeholder is routinely applied both by participants and analysts to cases that exhibit significant variance in the nature of relations instituted among the actors. This variation is typically evident in the relevant procedural rules that constitute those relations, a subject we return to below. One response to this empirical finding would be to declare that multistakeholder governance is simply a buzzword rather than an identifiable institutional form. Such a response would, in our view, amount to prematurely striking the tents. Actors seem eager both to talk about engaging in multistakeholderism and to engage in it - whether by speaking about it or in other ways. No doubt actors sometimes deploy the discourse of multistakeholderism for political purposes, but their decisions to do so themselves present an interesting puzzle: if the institutional form is ill-defined, why do actors find invoking it useful, and how are they invoking it to suit their purposes? We conclude that variation in the forms exhibited by instances of multistakeholderism does not provide grounds for abandoning the concept. Rather, it warrants the conclusion that there are several types of multistakeholderism. Adopting this stance enables further research on the development of this institutional form, and on the development of institutional forms in the international system more generally.

We also depart from the literature on multilateralism by defining multistakeholder governance as involving two or more classes of actors, rather than three or more (state) parties. Lexically, the prefix 'multi' can be used to refer to groups of two or more, or to groups of three or more. As we have no need to distinguish multistakeholder governance from bi-stakeholder governance (since there is not an existing literature on the latter), we have opted to define multistakeholderism more broadly. Our primary aim in this regard is to cast the analytical net as widely as possible, so as to maximize the applicability of our framework to empirical cases. We suspect, for instance, that members of various non-governmental organizations (NGOs) and civil society communities that routinely engage with firms might well understand these efforts to be examples of multistakeholder governance and would not want to foreclose that possibility by fiat. We recognize, however, that defining multistakeholder governance to include any case involving two or more classes of actors is a tentative analytic choice that may require revision in light of evidence from further research. 
We specify four classes of actors: states, formal intergovernmental organizations (IGOs), firms, and civil society actors. In doing so, we recognize that none of these four classes is beyond criticism or without complication. ${ }^{2}$ It might be desirable, for instance, to disaggregate the state, and to include at least some of its component parts in our framework separately. Independent regulatory agencies (such as the American Securities and Exchange Commission (SEC)) might be identified as an actor class on the basis that they often participate in transgovernmental networks with important roles in global governance. ${ }^{3}$ It might also be important to distinguish between various kinds of firms: for example, publicly-traded vs privately-held, purely domestic or transnational corporations, or manufacturing firms vs service providers. Similarly, our civil society actor class might also be criticized for including NGOs, social movements, civil society networks, and even individuals acting in their private capacities. ${ }^{4}$ Kenneth W. Abbott and Duncan Snidal opt to use NGOs as a category in their elaboration of the 'governance triangle'. They also opt against including IGOs as a category of actor, instead characterizing them as 'important vehicles through which states manage competition and advance common interests'. They justify this choice on the grounds that: (1) IGOs 'must ensure their organizational survival' and therefore 'may be unwilling to take strong stands against their members, even if doing so is part of their fundamental raison d'être'; and (2) that they 'can also develop organizational pathologies that divert them from their missions' (Abbott and Snidal 2009b). ${ }^{5}$

While we recognize that there may be good reasons to disaggregate our state, firm and civil society actor classes, we have opted not to do so here to avoid further complication in the typology of multistakeholder governance forms developed below. Further research could expand these categories in order to assess whether the analytical leverage gained outweighs the loss of parsimony. We do, however, believe that IGOs should be included as a separate actor category. There are four reasons we think this choice is appropriate. First, there are circumstances under which it is reasonable to expect that agents will possess significant autonomy from principals. ${ }^{6}$

\footnotetext{
${ }^{2}$ We owe several of the following possibilities to the excellent suggestions of the anonymous reviewers.

${ }^{3}$ On transgovernmentalism, see Slaughter (2004).

${ }^{4}$ There is now a voluminous literature on such non-state actors in world politics. One important example is Keck and Sikkink (1998).

${ }^{5}$ On the application of principal-agent theory to IRs, see also Hawkins et al. (2006).

${ }^{6}$ For a discussion of such circumstances in the context of international institutions and governance, see Abbott and Snidal (2000).
} 
Second, even if IGOs are in many cases constrained by the wishes of their member states, it does not necessarily follow that they should be omitted as a class of actor. After all, some members of each of the other three actor classes can plausibly be understood to face similar constraints. States, and especially democracies, can be understood as agents of their citizens; firms as agents of their owners or shareholders; and NGOs as agents of their members. Third, any concerns such as Abbott and Snidal's about the possibility of organizational pathology is similarly present in states, firms and civil society actors. Fourth, many IGOs have degrees of the 'essential capacities' that Abbott and Snidal associate with actors engaged in regulatory standard-setting processes: independence, representativeness, expertise, and operational capacity (Abbott and Snidal 2009a, b, 46). Therefore, we opt to include IGOs as a distinct actor class in our typology; however, we leave open the empirical question of the extent to which IGOs are actual participants in particular instances of multistakeholder governance. Based on four classes of actors, and the limiting condition that multistakeholder governance must involve at least two of the four classes, there are 11 possible combinations of actor types: a single combination of all four classes, four combinations of three classes and six combinations of two classes.

In order to qualify as multistakeholder governance, a case must also involve governance. This raises additional definitional complications. With respect to global governance, Thomas G. Weiss and Rorden Wilkinson have argued that 'imprecision has robbed the term of conceptual rigor'; while they do not advance a definition, they identify the need for further research in four areas: (1) historicizing the notion of global governance; (2) identifying and explaining 'structures of global authority'; (3) investigating 'the myriad ways that power is exercised within such a system'; and (4) improving the discipline's ability to 'account for changes in and of the system' by focusing on 'the causes, consequences, and drivers of change' (Weiss and Wilkinson 2014, 207). James N. Rosenau deliberately advanced a capacious definition, which conceived global governance 'to include systems of rule at all levels of human activity - from the family to the international organization - in which the pursuit of goals through the exercise of control has transnational repercussions'. He refined this conception slightly in arguing that governance 'encompasses the activities of governments, but it also includes the many other channels through which "commands" flow in the forms of goals framed, directives issued, and policies pursued' (Rosenau 1995, 13-14). The research agenda advanced by Weiss and Wilkinson, and the conception of governance provided by Rosenau, are both extremely useful in thinking about (global) governance. They are less helpful for deciding what counts (and does not count) 
as governance. For the purposes of our analysis here, we adopt a definition recently developed by David A. Welch in collaboration with students in a graduate seminar; they define governance as 'the coordinated, polycentric management of issues purposefully directed toward particular outcomes' (Welch 2013, 257). The strengths of this definition for our purposes in examining the phenomenon of multistakeholder governance are its agnosticism with respect to precisely how issues are handled and to the identity of the actors handling them, and its recognition that governance is polycentric in nature.

While Welch's crowdsourced definition is useful, two issues require further comment. First, governance (like government) is concerned with managing issues understood by the actors involved to be of shared concern, or part of the public sphere. Thus, we exclude from our conception of multistakeholder governance any arrangements concerned primarily with actors' private conduct. However, in so doing, we note that the boundaries of the public sphere are socially constructed rather than natural and fixed. Therefore, the relevant standards for determining whether a particular matter is public or private (and thus legitimately a potential matter of governance or not) are those of the actors rather than of the analyst. Actors contest such boundaries, and the content of their shared agendas; the Internet governance cases examined below demonstrate a great deal of this kind of contention. In noting the public nature of governance, though, it is crucial to remember that this does not entail restriction of participation exclusively to public actors. Private and civil society actors expend a great deal of effort to influence the management of public issues, for a variety of reasons having to do with both their interests and values. Furthermore, relevant procedural rules increasingly accord them the ability, and in some cases even the right, to do so. These procedural innovations are crucial to the emergence of multistakeholderism as an institutional form. ${ }^{7}$

Second, the Welch definition treats governance as inherently polycentric a quality seemingly similar to multistakeholderism; however, the two are not identical, as a particular instance of governance may not include multiple actor types. The original articulation of polycentric governance was provided by Vincent Ostrom, Charles M. Tiebout and Robert Warren, who wrote that polycentricity 'connotes many centers of decision making that are formally independent of one another'. They noted further that 'whether they actually function independently, or instead constitute an

${ }^{7}$ On the notion of a global public sphere and on emerging shifts in its nature, see Ruggie (2004). 
interdependent system of relations, is an empirical question in particular cases' (Ostrom et al. 1961, 831-32; see also Ostrom 2010). Rather than being a rare or special condition, polycentricity thus defined is in fact incredibly common. Most important for our purposes here, it does not require the involvement of multiple classes of actors. Thus, a diplomatic arrangement between states qualifies as polycentric but not multistakeholder. So, too, does the creation of an industry association of firms. In contrast, we find it difficult to conceive of multistakeholder governance that is not polycentric. Such polycentrism can take at least two forms. The first involves an arrangement wherein multiple actor types participate in the operation of a dominant organization responsible for governing a particular issue, or what Büthe and Mattli have called a focal institution (Büthe and Mattli 2011, 5, 18-20). The Internet Corporation for Assigned Names and Numbers (ICANN) is such an example with respect to the administration of the Internet's domain name system (DNS). The second type of polycentrism consistent with our notion of multistakeholderism more closely resembles a regime complex. A regime complex involves multiple issuespecific regimes with overlapping membership and subject-matter, as well as 'problematic interactions' between the individual regimes (Orsini et al. 2013, 29). To qualify as a case of multistakeholder governance, a regime complex would need to include at least two classes of actors. Joseph S. Nye has argued for shifting analytical focus from the narrow Internet governance regime to a broader cyber regime complex that includes all four classes of actors we identify (Nye 2014). The coexistence of both kinds of polycentrism within one issue-area illustrates the diversity of particular cases of the general class of multistakeholderism, in line with our argument.

These types of polycentrism illustrate the importance of Ruggie's focus on the nature of relations among actors in constituting particular institutional forms. We proceed along the same analytical lines, but reach a different conclusion about the degree of coherence in the generic institutional form of multistakeholderism than Ruggie reached with respect to multilateralism. To the extent possible, we identify conceptual boundaries for the kinds of relations among actors consistent with multistakeholderism as an institutional form. Governance arrangements can vary according to the nature of the authority relations among actors. This manner of variation is appropriately absent from Ruggie's discussion of multilateralism as an institutional form because the intersubjective understandings and social practices that constitute it limit participation to states and enshrine participation on the basis of formal sovereign equality. These features are inherent to Ruggie's thick definition of multilateralism as 'an institutional form which coordinates relations among three or more states on the basis of "generalized" principles of conduct - that is, principles which specify 
appropriate conduct for a class of actions, without regard to the particularistic interests of the parties or the strategic exigencies that may exist in any specific occurrence' (Ruggie 1992, 571). Christian Reus-Smit characterizes modern international legal multilateralism in a similar fashion, as comprising 'the principle that social rules should be authored by those subject to them' and 'the precept that rules should be equally applicable to all subjects, in all like cases' (Reus-Smit 1999, 9). Both the class of actor and the nature of authority relations in this institutional form are fixed, rendering a typology of the kind we construct unnecessary to the analysis of multilateralism.

Instances of multistakeholder governance are far less uniform and consistent. We argue that this is in large part due to significant variation in the nature of authority relations among actors. We specify four ideal-typical possibilities: hierarchy, heterogeneous polyarchy, homogeneous polyarchy, and anarchy. Hierarchy entails relations of super- and subordination, where one is entitled to command and others have a duty to obey. Polyarchy entails situations where authority is distributed among a number of actors (see Dahl 1956, 1972). ${ }^{8}$ This kind of distribution can be done in a heterogeneous manner in which distinct actors (or classes of actors) possess different formal powers (such as the division of authority between branches of government). It can also be done in a homogeneous manner, where actors have similar formal powers (such as individual voters in a democracy where each citizen receives an equal vote). As these examples make clear, actual systems of governance may blend elements of these ideal types. The fourth possibility is anarchy, a situation in which no authority relations exist. Of these four, we argue that only the two forms of polyarchy are consistent with multistakeholderism as an institutional form.

Though anarchy has been at the foundation of IR as an academic discipline (see, e.g., Waltz 1979; Bull 2002), we discard the possibility of anarchic relations between actors (or classes of actors) engaged in a common governance enterprise. We do so on the basis of recent scholarship showing the presence of varying kinds and degrees of authority in international history (see, e.g., Hobson and Sharman 2005; Keene 2007; Sharman 2013), and on the basis that IR theory has erred in typically attributing authority solely to actors (Hurd 1999; Raymond 2015). Authority is also a potential property of rules. In order for a common governance enterprise to exist, it is necessary that actors mutually accept the authority of a set of rules (however limited) that establishes the scope of the common governance enterprise, the kinds of actors entitled to participate in

\footnotetext{
${ }^{8}$ For a review of Dahl's scholarship in broader context, see Krouse (1982).
} 
governance, and the terms of that participation - including the way disputes about the application of general rules to particular cases will be handled. Many of these rules are procedural in nature, a topic to which we return below. Even if actors are equally empowered by these rules to participate in the alteration, operation and termination of the governance arrangement in question, it is still accurate to describe the situation as containing authority relations; it is merely a special case where authority is shared equally and symmetrically. Equally shared authority should not be mistaken for the absence of authority. This mistake has unfortunately been all too common in a discipline defined by a binary juxtaposition of hierarchy and anarchy. A weak version of this claim about the ubiquity of authority relations (though not hierarchy) in governance arrangements would be constrained to the empirical domain with which this article is concerned - the institutional form of multistakeholderism - and would suggest only that anarchy drops out of the multistakeholder governance typology developed here.

A strong version of our claim about authority relations has wide-ranging implications for IR theory. A full exploration of these implications is beyond the scope of this article, but we want to make a few provisional remarks. First, the category error of treating authority as a binary property attributable only to actors and not also to rules has obscured a great deal of authority in the international system. If authority relations are instead understood in terms of the four categories identified here (hierarchy, heterogeneous and homogeneous polyarchy, and anarchy), it suggests that IR theory has miscoded the international state system as an instance of anarchy. Since international law and diplomacy as fundamental institutions of international society are themselves authoritative rule-sets and since they (at least in their modern variants) also empower state actors to make and alter international rules on a formally equal basis, there is a case for understanding the contemporary state system as a case of homogeneous polyarchy $;{ }^{9}$ however, this, too, is a simplification. As Hobson and Sharman (2005) have pointed out, the main actors in the international system over most of its history have been empires; thus, the system has historically contained elements of hierarchy in that imperial states and their colonies were differentially empowered in the operation, alteration and interpretation of international rules. This is only a single example of a fundamentally important point. A great deal more thinking and research are required

${ }^{9}$ What is coded as 'anarchy' in IR theory might also be understood, in similar terms, as what Ostrom et al. (1961) define as polycentricity - namely, 'many centers of decision making that are formally independent of one another.' Since Ostrom, Tiebout and Warren wrote about governance of metropolitan areas, it is clear that they did not understand these actors as operating in a context entirely devoid of authority relations. 
to better understand authority relations in the international system. Accordingly, we proceed in this article on the basis of the more limited claim that potential instances of anarchy fall outside of the institutional form of multistakeholderism.

While authority relations clearly exist in the international system (Hurd 1999; Hobson and Sharman 2005; Keene 2007, 2013; Lake 2007, 2009; Sharman 2013), highly hierarchical social relations are not consistent with multistakeholderism as an institutional form. Ideal-typical hierarchy leaves little room for agency on the part of the subordinate actor in core governance tasks including rule-making, interpretation and application. In such cases, the subordinate actor is a clear rule-taker. Accordingly, highly subordinate actors are not meaningful participants in governance; rather, they are the governed. For this reason, we also omit hierarchy from the kinds of relations among actors consistent with multistakeholderism.

However, it does not follow from the exclusion of ideal-typical hierarchy that authority is irrelevant to multistakeholderism. The four kinds of authority relations we identify are ideal types. In this sense, our framework departs from the IR literature on anarchy and hierarchy in treating authority relations as variegated rather than binary. Lake has suggested treating hierarchy as a continuous variable (Lake 2007, 56). While this treatment is an advance over traditional binary understandings of the relationship between anarchy and hierarchy, we prefer to think in terms of distinct types of authority relations. This move is crucial to our introduction of homogeneous and heterogeneous polyarchy, and to understanding multistakeholderism as an institutional form. Variation among different kinds of authority relations is not purely a matter of there being more or less of exactly the same kind of thing. Rather, individual instances of authority relations 'are defined by shared rules and understandings that constitute them' (Raymond 2015). It follows from this that there can be substantial within-category variation among instances of both heterogeneous and even homogeneous polyarchy. That is, two different governance arrangements might be roughly equally heterogeneous in the way they distribute authority among participating actors and yet exhibit important institutional differences. ${ }^{10}$ If authority is thought of only, or even primarily, as varying in quantity rather than kind, this variation is rendered invisible. We believe that this more granular understanding of authority relations serves as a corrective both to the literature on anarchy and also to the emerging

${ }^{10}$ One such example is the contrast between ancient Greek city-states and the contemporary international system in Reus-Smit (1997). While Reus-Smit described these cases as different anarchies, if we are right about the authoritative nature of rules and institutions in constituting actors, these cases can be reconceived as (non-multistakeholder) homogeneous polyarchies. 
Table 1. Types of multistakeholder governance

\begin{tabular}{|c|c|c|c|c|}
\hline \multirow[b]{3}{*}{ Stakeholder types } & \multicolumn{4}{|c|}{ Nature of authority relations } \\
\hline & \multirow[b]{2}{*}{ Hierarchy } & \multicolumn{2}{|c|}{ Polyarchy } & \multirow[b]{2}{*}{ Anarchy } \\
\hline & & Heterogeneous & Homogeneous & \\
\hline \multicolumn{5}{|c|}{ States, IGOs, firms, NGOs } \\
\hline \multicolumn{5}{|c|}{ States, IGOs, firms } \\
\hline \multicolumn{5}{|l|}{ IGOs, firms, NGOs } \\
\hline \multicolumn{5}{|l|}{ States, IGOs, NGOs } \\
\hline \multicolumn{5}{|l|}{ States, firms, NGOs } \\
\hline \multicolumn{5}{|l|}{ States, IGOs } \\
\hline \multicolumn{5}{|l|}{ States, firms } \\
\hline \multicolumn{5}{|l|}{ States, NGOs } \\
\hline \multicolumn{5}{|l|}{ IGOs, firms } \\
\hline \multicolumn{5}{|l|}{ IGOs, NGOs } \\
\hline Firms, NGOs & & & & \\
\hline
\end{tabular}

$\mathrm{IGO}=$ intergovernmental organizations; $\mathrm{NGO}=$ non-governmental organization.

literature on hierarchy. However, more importantly for our purposes here, it highlights the connection between variation in procedural rules and variation in types of authority relations. We return to this issue in the final substantive section of the article.

Combining the 11 possible combinations of actor types with the two categories of authority relations consistent with multistakeholderism yields 22 possible forms of multistakeholder governance (indicated by the shaded portion of Table 1). ${ }^{11}$ This typology serves three purposes. First, it is a mechanism for identifying and classifying key features of actual cases. Second, we expect it will also be useful in identifying (and ideally explaining) clusters and gaps in the distribution of actual governance institutions and processes; we do not expect that the actual universe of cases will be equally distributed among these possible forms. Third, with further research on the effectiveness of various governance modalities for specific kinds of issue areas and governance functions, the typology presented here could assist in improving governance effectiveness by more appropriately

${ }^{11}$ As only a single actor class is involved in multilateralism, it obviously does not appear in our typology. However, for purposes of comparing the institutional form of multilateralism with the institutional form of multistakeholderism, it is useful to note that the authority relations between state actors participating in multilateralism correspond closely to the category of homogeneous polyarchy in our table. 
matching governance functions with particular governance processes, mechanisms and institutions. ${ }^{12}$ With this typology in mind, the following sections examine several cases of multistakeholder governance that vary based on the types of actors involved and the nature of authority relations between actors.

\section{A comparative study of multistakeholder governance as a class of phenomena}

As a small but representative selection of cases of multistakeholder governance, this section will examine the administration of Internet names and numbers by the ICANN, standards setting by the Internet Engineering Task Force (IETF), international telecommunications regulation by the United Nations International Telecommunication Union (ITU), aspects of global financial governance by the IOSCO, and emerging governance of corporate social responsibility by the United Nations GC.

A significant motivation for conceptually examining multistakeholderism emanates from prevailing global controversies over how the Internet is controlled, and uncritical and unexplained assertions that the Internet is, or should be, governed in a multistakeholder arrangement. As such, we were compelled in our own cases to include ICANN (the institution around which the majority of global deliberation on Internet governance revolves) and the ITU (an organization historically proposed as an alternative for taking over key functions of Internet governance, including some narrow tasks performed by the United States government). In contrast to the turbulent global negotiations over the roles of ICANN and the ITU, the IETF has had a relatively uncontroversial, long, and well-regarded history in Internet governance so we include it for comparison. The fourth and fifth cases were included to complement the Internet governance issue area and were selected because they are themselves described as multistakeholder. The inclusion of cases outside of Internet governance serves as a check on prevailing discourses suggesting that multistakeholderism is unique to this issue area, which we argue it is not. Collectively, the cases exhibit variation in terms of the combination of actor classes, the issues involved, and the forms of multistakeholderism employed. In the final section of the paper, we allude to several other potential cases not examined in detail here. These and other cases offer opportunities for further research extending the framework we develop.

12 Expectations for such improvements should remain modest, however, given path dependency and the general inefficiency of institutional change. For arguments along these lines, see: March and Olsen (1998); Wendt (2001). 


\section{Disaggregating multistakeholder Internet governance}

An examination of cases of multistakeholder governance reasonably begins with governance of the Internet, both because it is an area so often considered multistakeholder and also because of the rising importance of Internet coordination and oversight to economic, political and social life. Questions about the Internet's security and stability have emerged as a crucial international political concern on par with more longstanding global problems such as environmental protection, human rights, and basic infrastructural systems of finance, telecommunications, water, and energy. These shared global issues transcend national borders and sovereignty. No state acting alone can address these issues in toto; yet, local actions within national borders can have significant network externalities that reach across the globe. ${ }^{13}$

While Internet governance includes important instances of multistakeholder governance, and while preserving that model is a primary goal for the broader Internet community as well as for many governments, it is important to note that Internet governance is not a monolithic enterprise. Rather, it involves layers of distinct coordinating and administrative tasks that cumulatively keep the Internet operational. Many of these functions are accomplished in non-multistakeholder ways. Before turning to particular cases of Internet governance, therefore, we make the case for a more nuanced and disaggregated understanding of the broader landscape.

For the majority of its history, the Internet has been governed in a piecemeal fashion by a variety of standard setting and other technical bodies and by private companies performing key roles as network operators and information intermediaries. It is thus an excellent example of the power of epistemic communities to shape governance. ${ }^{14}$ This legacy has generated two predominant characteristics of Internet governance arrangements. First, with a few notable exceptions, states have been either generally uninvolved or involved only as participants without superordinate decision-making authority. ${ }^{15}$ Second, decision making for Internet governance has typically been driven by technical and market considerations. In terms of institutionalist IR scholarship, coordination problems have been more common than

\footnotetext{
${ }^{13}$ While some transboundary issues pose problems of managing common pool resources, it can be argued that the Internet is not itself a commons. Given its non-rivalrous and excludable nature, it is more accurately thought of as a set of nested club goods. See Raymond (2013b).

14 On epistemic communities, see Haas (1992).

15 This feature encapsulates part of what has been referred to as networked governance, see Mueller et al. (2013).
} 
cooperation problems. ${ }^{16}$ These features, and especially the general lack of an authoritative role for states, have led both scholars and practitioners to conclude that the Internet is an example of multistakeholder governance. ${ }^{17}$

The computing devices and content to which end users are exposed constitute only the surface of a massive underlying infrastructure of networks, services, and institutions that keep the Internet operational. Most of this material and virtual architecture is comprised of private information intermediaries such as network operators, exchange points, search engines, hosting services, e-commerce platforms, and social media providers. Despite the privatized and somewhat autonomous nature of these network components, global coordination is necessary to keep the overall Internet operational. Global technical standardization ensures interoperability; cybersecurity governance maintains stability and authentication; and centralized coordination ensures that each Internet name and number is globally unique. These, and other, tasks necessary to keep the Internet operational, as well as the substantive public policy issues that arise around these functions, are collectively referred to as 'global Internet governance'.

Internet governance has sometimes been viewed by policymakers and scholars as a monolithic system. Hence, policy deliberations and scholarship examining multistakeholderism have analogously sought a uniform definition of what counts as participatory and diverse governance. Various definitions also reflect historically specific power struggles and stakeholder interests. The definition of Internet governance emerging from the aftermath of the 2003 World Summit on the Information Society (WSIS) in Geneva, Switzerland serves as an exemplar of such homogeneity and politicization. Kofi Annan, then-Secretary-General of the United Nations, established a Working Group on Internet Governance (WGIG) as a response to open issues over control of the Internet left unresolved at WSIS. ${ }^{18}$ The working group, which included 40 participants from governments, private sector, and civil society, was charged with developing a definition of Internet governance, which it devised as follows:

'Internet governance is the development and application by Governments, the private sector and civil society, in their respective roles, of shared principles, norms, rules, decision-making procedures, and programmes that shape the evolution and use of the Internet' (Working Group on Internet Governance 2005).

${ }^{16}$ On the different implications of these styles of games, see Martin and Simmons (1998). See also Krasner (1991).

${ }^{17}$ For one example, see Cerf et al. (2014).

${ }^{18}$ For background about the WSIS process, see Stauffacher and Kleinwächter (2005). 
The context from which this arose was politically charged and historically specific. There was mounting political concern over the unique and enduring role of the United States Commerce Department in contracting with ICANN to perform the global administration of Internet names and numbers. The states represented in the WSIS/WGIG process were primarily concerned with what they perceived as unilateral American control of the Internet. The ITU, the United Nations specialized agency for information and communication technologies, was also increasingly stressing its intergovernmental legitimacy as a rationale for attempting to take a greater role in both names and numbers administration and Internet standards governance, vs the prevailing administrative role of ICANN and predominantly private industry contributions in various standards-setting entities including the IETF. Within this context, the WGIG definition conveyed some strong normative positions. The definition assigned an Internet governance role to 'Governments,' commensurate with global interest in greater multilateral administration and potentially a unique role for intergovernmental entities such as the United Nations in Internet oversight.

The composition of the WGIG did not represent key constituencies with a stake in the outcome of the definition or those with responsibility for Internet governance in practice. The United Nations group did not significantly include the input of large Internet users (e.g. corporations relying on the Internet for financial and business transactions and basic operations); private sector companies involved in provisioning Internet products or providing infrastructure; or any representatives from the leading standards setting and administrative entities operationally responsible for the security and stability of the Internet. The United States chose not to participate in the working group. Of the 40 members, the majority of participants were high-level governmental officials involved in national technology policy. Many of these officials represented countries (e.g. Saudi Arabia, Pakistan, Cuba, China, Egypt, Tunisia, Russia, Iran) with notoriously repressive Internet policies (Working Group on Internet Governance 2005).

Thus, the formulation of an international definition of multistakeholderism was arguably not a multistakeholder effort. In addition, sometimes lost is that the convocation of the United Nations Internet Governance Forum (IGF), first held in Athens, Greece in 2006, was a compromise emanating from an impasse over UN and governmental calls for a diminishment of US coordination of certain Internet administrative functions and American resistance to these recommendations. The IGF was formed to create an international space for multistakeholder dialog about Internet policy. These multistakeholder gatherings have been distinct from the actual practice of Internet governance; rather, they are deliberations about Internet policy. 
International gatherings, as 'talk shops,' potentially have an agenda-setting and framing function but at least thus far realistically have limited influence over policymaking in practice (Dutton et al. 2007).

This distinction between Internet governance discourse vs. praxis highlights a prevailing feature of scholarship on multistakeholderism. Many examinations interrogate the question of who can contribute to discussions about Internet governance, particularly in the WSIS/WGIG/IGF context, rather than who can contribute to the actual practice of Internet governance (see, e.g., Malcolm 2008; Epstein 2013). Although this question about multistakeholder dialog is valuable sui generis, it does not directly address the question of how Internet coordination does or should occur in practice.

Within the actual practice of Internet governance, the phrase multistakeholderism is too often employed uniformly and uncritically. It is a misnomer to speak of the multistakeholder model for Internet governance. A question such as 'who should control the Internet: the United States, the United Nations, or some other entity,' is incongruous because it inherently assumes that Internet governance is a singular system, and also completely discounts the highly privatized nature of Internet administration. There is no unitary system that oversees and coordinates the Internet. Some tasks are carried out by private industry operating as part of markets; some tasks are overseen by relatively new institutions such as the ICANN; and some administrative jurisdiction resides with sovereign states or multilateral governmental coordination.

Explanations of the various tasks of Internet governance and associated taxonomies abound (see, e.g., Mathiason 2008; Bygrave and Bing 2009; Mueller 2010; Brousseau et al. 2012; DeNardis 2014). One way to understand the Internet governance ecosystem is to divide its main functions into six areas: (i) control of 'critical Internet resources,' (ii) setting Internet standards, (iii) access and interconnection coordination, (iv) cybersecurity governance, $(\mathrm{v})$ the policy role of information intermediaries, and (vi) architecture-based intellectual property rights enforcement.

Critical Internet resources are the globally unique virtual identifiers including domain names, Internet Protocol (IP) addresses, and autonomous system numbers - necessary for the day-to-day operation of the Internet, as well as the DNS, a distributed set of servers that translates domain names into associated IP addresses for routing information to its destination. Internet standards are the common rules, or protocols, that computing devices follow to ensure global interoperability (e.g. TCP/IP, VoIP). Access and interconnection coordination addresses how various networks conjoin to collectively form the global Internet and the regulation of access, such as net neutrality rules. Cybersecurity governance encompasses the challenge of securing the essential shared infrastructures of Internet governance, 
including routing, authentication systems, and the DNS, as well as responding to Internet security problems like worms and distributed denial of service attacks. The policy role of private information intermediaries (e.g. Google, Facebook) includes functions such as the formulation of subscriber privacy rules or responding to government censorship and lawful intercept requests. Architecture-based intellectual property rights enforcement addresses the turn to infrastructure for copyright enforcement as well as intellectual property rights embedded within Internet governance infrastructure, such as the adjudication of domain name trademark disputes.

Table 2 disaggregates Internet governance into these six functional areas and then further into 43 specific tasks of administrative responsibility. The table also lists the primary, although often not exclusive, institutional actor historically responsible for executing each task. For example, under the functional area of Internet standardization, one critical task is the establishment of standards for the web, such as HTML and XML, primarily carried out institutionally by the World Wide Web Consortium (W3C).

The table captures several features of how Internet governance actually works. Most obviously, Internet governance is not a singular enterprise; the coordination and administration of the Internet involves many layers of distinct tasks. Equally evident, the Internet does not just autonomously 'work' but remains operational via considerable, and sometimes costly, administrative coordination. This reality sits uneasily with some parts of the Internet community that embrace what can be thought of as cyberlibertarianism; this view is encapsulated in the conviction that 'legal concepts of property, expression, identity, movement, and context do not apply [online]...they are all based on matter, and there is no matter here' (Barlow 1996). There is, of course, matter: buildings, power supplies, switches, fiber optic equipment, routers, and undersea cables. Many scholarly approaches from law, economics, and communication inherently focus on content, applications or usage and do not reach into many of the material and virtual technological functions of Internet governance.

A disaggregated Internet governance taxonomy also helps illustrate a connection between functional technological governance areas and direct public policy formulation. For example, intellectual property rights enforcement approaches designed to block access to users who have repeatedly downloaded copyrighted material have accompanying implications for freedom of expression, access, and due process (Dutton et al. 2011). Similarly, private industry mediation of government content removal requests, and the decision to comply with or reject these requests, establishes conditions of what counts as free expression in the digital public sphere (Balkin 2008). These connections between technical coordination and public policy and the reality of highly privatized governance raise questions about adequate conditions of 
Table 2. Disaggregated Internet governance taxonomy

\begin{tabular}{lll}
\hline \hline & \multicolumn{1}{c}{ Disaggregated Internet governance taxonomy } \\
\hline Functional area & Tasks & Primary institutional actor \\
\hline I. Control of 'Critical Internet Resources' & Central oversight of names and numbers & ICANN, IANA, US DoC \\
& Technical design of IP addresses & IETF \\
& New top-level domain approval & ICANN \\
& Domain name assignment & Internet registrars \\
& Authorization of root zone file changes & US DoC/NTIA \\
& IP address distribution (allocation/assignment) & IANA, RIRs, LIRs, NIRs, ISPs \\
& Management of root zone file & IANA \\
& Autonomous system number distribution & IANA, regional Internet registries \\
& Operating Internet root servers & VeriSign, cogent, others \\
& Resolving DNS queries (billions per day) & Registry operators (VeriSign, others) \\
& Protocol number assignment & IANA \\
& Designing core Internet standards & IETF \\
& Designing core web standards & W3C \\
II. Setting Internet standards & Establishing other communication standards & ITU, IEEE, MPEG, JPEG, ISO, others \\
& Facilitating network interconnection & Internet exchange point operators \\
& Peering and transit agreements to interconnect & Private network operators, content networks, CDNs \\
& Setting standards for interconnection (e.g. BGP) & IETF \\
& Network management (quality of service) & Private network operators \\
& Setting end user access and usage policies & Private network operators \\
& Regulating access (e.g. net neutrality) & National governments/agencies
\end{tabular}


Table 2. (Continued)

\begin{tabular}{|c|c|c|}
\hline \multicolumn{3}{|c|}{ Disaggregated Internet governance taxonomy } \\
\hline Functional area & Tasks & Primary institutional actor \\
\hline IV. Cybersecurity governance & $\begin{array}{l}\text { Securing network infrastructure } \\
\text { Designing encryption standards } \\
\text { Cybersecurity regulation/enforcement } \\
\text { Correcting software security vulnerabilities } \\
\text { Software patch management } \\
\text { Securing routing, addressing, DNS } \\
\text { Responding to security problems } \\
\text { Trust intermediaries authenticating web sites }\end{array}$ & $\begin{array}{l}\text { ISPs, network operators, private end user networks } \\
\text { Standards-setting organizations } \\
\text { National statutes/multilateral agreements } \\
\text { Software companies } \\
\text { Private end users } \\
\text { Network operators, IETF, registries } \\
\text { CERTs/CSIRTs } \\
\text { Certificate authorities }\end{array}$ \\
\hline V. Information intermediation & $\begin{array}{l}\text { Commercial transaction facilitation } \\
\text { Mediating government content removal requests } \\
\text { (discretionary censorship) } \\
\text { App mediation (guidelines, enforcement) } \\
\text { Establishing privacy policies (via end user agreements } \\
\text { and contracts) } \\
\text { Responding to cyberbullying and defamation } \\
\text { Regulating privacy, reputation, speech } \\
\text { Mediating government requests for personal data }\end{array}$ & $\begin{array}{l}\text { E-commerce sites, financial intermediaries } \\
\text { Search engines, social media companies, content } \\
\text { aggregation sites } \\
\text { Smartphone providers (e.g. Apple) } \\
\text { Social media, advertising intermediaries, E-mail } \\
\text { providers, network operators } \\
\text { Content intermediaries } \\
\text { Statutory and constitutional law } \\
\text { Content intermediaries, network operators }\end{array}$ \\
\hline
\end{tabular}


Table 2. (Continued)

\begin{tabular}{lll}
\hline \hline & \multicolumn{2}{c}{ Disaggregated Internet governance taxonomy } \\
\hline Functional area & Tasks & Primary institutional actor \\
\hline $\begin{array}{l}\text { VI. Architecture-based intellectual property } \\
\text { rights enforcement }\end{array}$ & Domain name trademark dispute resolution & $\begin{array}{c}\text { ICANN UDRP, registrars, accredited dispute } \\
\text { resolution providers } \\
\end{array}$ \\
& Removal of copyright infringing content & Content intermediaries \\
& Algorithmic enforcement (e.g. search rankings) & Search engine companies \\
& Blocking access to infringing users & Network operators/ISPs \\
& Domain name system IPR enforcement & Registries/registrars \\
& Regulating online IPR enforcement & National statutes, international treaties \\
& Standards-based patent policies & Standards-setting organizations \\
& Enacting trade secrecy in content intermediation & Search engines, reputation engines \\
\hline \hline
\end{tabular}

ICANN = Internet Corporation for Assigned Names and Numbers; IP = Internet protocol; IANA = Internet Assigned Numbers Authority; DNS = domain name system; IETF = Internet Engineering Task Force; W3C = World Wide Web Consortium; NTIA = National Telecommunications and Information Administration; RIRs = regional Internet registries; ITU = International Telecommunication Union; ISO = International Organization for Standardization. 
accountability, transparency, and oversight for non-governmental actors to make and carry out such public policy.

Even such an extensive taxonomy misses part of how Internet governance works. Contextual factors like technological constraints, economic conditions, and social and cultural forces all shape the nature of this governance. For example, civic (as well as corporate) engagement influenced the failure of the Stop Online Piracy Act and PROTECT IP Act in the United States Congress in 2012.

Even with these limitations, there are rational reasons to disaggregate Internet governance as practiced into specific functions. These functions are performed by different types of actors. They also involve a variety of distinct governance activities such as contracting, deliberating, legislating, standard setting, regulating, adjudicating and enforcing.

This disaggregation also demonstrates that existing Internet governance arrangements vary in the classes of actors involved, and not all clearly meet the first criterion of multistakeholder governance provided above. Several specific functions of Internet governance are not multistakeholder at all because they involve a single actor or single class of actor. Many Internet governance functions have traditionally been governed solely by firms. An example involves the private contractual arrangements among private network operators to conjoin their networks at bilateral interconnection points or shared Internet Exchange Points. Private Internet registries like VeriSign oversee the operation of generic top-level domains (gTLD). Network operators carry out network management tasks and respond to security problems on their private networks. Media companies set privacy policies to which users must agree before using these services. These are clear instances of how some Internet governance in practice does not currently meet our first, minimal, criterion for multistakeholder governance (or how policymakers and the media describe Internet governance). This privatization of oversight is a dominant feature of how Internet governance has evolved in practice.

Some functions are also relegated to the state, such as multilateral treaties about intellectual property rights enforcement. One contentious example is the authorization of changes to the Internet's root zone file ${ }^{19}$ by an agency of the United States Department of Commerce known as the National Telecommunications and Information Administration (NTIA), although the United States announced in 2014 that it would transition this unique oversight to a global multistakeholder entity. International tension about

19 The root zone file (or root zone database) is the definitive list of IP addresses for servers for top-level domains, including country code top-level domains. 
how this transition would occur, as well as the privatized and contextually shaped nature of Internet governance and longstanding tensions between territorial state jurisdiction and non-territorial technological modes of communication, help explain the recent public attention to what counts as 'multistakeholder governance' in each layer of Internet governance.

The key point for our purposes here is that, contrary to popular narratives, much of Internet governance is not multistakeholder. However, the issue area does include important cases of the institutional form. We examine three potential cases, and find significant variation, including two very different forms of multistakeholderism and a third case (the ITU) that we ultimately classify as primarily hierarchical in terms of the relations among classes of actors.

\section{ICANN}

Considerable Internet governance scholarship focuses on the governance functions over critical Internet resources enacted by ICANN and the form of multistakeholderism that has arisen in ICANN (see, e.g., Mueller 2002; Antonova 2008). ICANN is a private, non-profit corporation (incorporated in California) formed in 1998 under contract with the United States government to administer the Internet's names (e.g. cnn.com) and numbers (the globally unique binary addresses assigned to computing devices, similar to postal addresses only virtual rather than physical). ICANN, and its Internet Assigned Numbers Authority (IANA) function, carries out a number of distinct functions including: allocation of blocks of Internet numbers to regional Internet registries (RIRs) for further distribution; oversight of the Internet's root server system operations; the establishment of policies for introducing new top-level domains to the root system; oversight of domain name assignment, albeit delegated to Internet registrars; assignment of unique protocol parameters; and management of the root zone file.

The technical design decision requiring globally unique names and numbers to use the Internet created an accompanying need to ensure that each name and number is globally unique. The combination of this requirement for centralized control, the fact that there is a finite pool of these resources, and the criticality of these resources for the ability to use the Internet, has over time shaped a certain form of multistakeholderism. In the Internet's early history, a single individual, Jon Postel, administered names and numbers. In the context of Internet growth and globalization, this coordination institutionally evolved and eventually came under the auspices of ICANN. ${ }^{20}$

${ }^{20}$ For an extensive description of ICANN functions and associated history, see Mueller (2002). 
While ICANN and its subsidiary organization IANA carry out highly technical administrative functions, these functions have significant global public policy implications. ${ }^{21}$ For example, the expansion of top-level domains (.xxx, .wine, .amazon, .gay) raises public interest issues related to intellectual property rights, free speech, and stakeholder interest disputes between territorial states vs global corporations. Because of the significant number of stakeholders with an interest in critical Internet resources, the coordinating functions ICANN performs are viewed as inherently multistakeholder.

In terms of actors, the organization has a Chief Executive Officer and a Board, each of which have particular authorities within the organization. Board members are selected by various stakeholder organizations (e.g. the Address Supporting Organization representing RIRs) and an independent nominating committee, itself made up of representatives from several supporting organizations and advisory committees. ${ }^{22}$

ICANN has three Supporting Organizations ${ }^{23}$ and four Advisory Committees (the Governmental Advisory Committee (GAC), the Security and Stability Advisory Committee, the Root Server System Advisory Committee, and the At-Large Advisory Committee). While each of these entities is empowered by ICANN's procedural rules to do certain things, their formal roles differ. The GAC is especially noteworthy; it is unique among ICANN's component units in that when it issues formal advice to the ICANN Board, the Board is required either to adopt the GAC's advice or to formally justify its refusal to do so, in writing, to the GAC. This provides the GAC (and thus its member governments) with a degree of authority over ICANN operations. GAC membership is open to national governments but IGOs and treaty organizations often participate under observer status (e.g. the Organization for Economic Co-operation and Development (OECD), the Council of Europe, the World Intellectual Property Organization, ITU, and others).

There has been international tension over the historic relationship between the United States Department of Commerce, specifically the NTIA, and control of a narrow but important set of Internet governance functions, including oversight of the Internet's root zone file that definitively tracks the list of names and IP addresses of all the authoritative servers for top-level

${ }^{21}$ See DeNardis (2014, Ch. 2) for a comprehensive list of the policy implications of Internet names and numbers.

22 See ICANN By-laws Article VII, Section 2, available at https://www.icann.org/resources/ pages/bylaws-2012-02-25-en\#VII-1.

${ }^{23}$ The Generic Names Supporting Organization, the Address Supporting Organization, and the Country Code Names Supporting Organization. 
domains (e.g. .com, .edu., .uk). ICANN (via IANA) continues to administer the Internet's root on the basis of an agreement with the US government. The symbolic and practical implications of this American oversight have created pressure for greater internationalization of this narrow function and have more generally created tension in Internet governance debates.

In 2014, the Department of Commerce announced its intention to transition its historic oversight of Internet names and numbers, and specifically, the IANA functions, to a 'global multistakeholder community' (NTIA 2014). This announced transition, as well as a number of Internet governance controversies such as 2013 disclosures about the expansiveness of US National Security Agency surveillance, drew a great deal of public and media attention to the question of who controls the Internet and, by extension, considerable scrutiny over the structure and evolution of multistakeholder governance in ICANN.

ICANN is a clear example of Internet governance involving multiple types of stakeholders, including participants from corporations, civil society and governments. Further, ICANN can be classified as a heterogeneous polyarchy. Authority over distinct functions is distributed among various actors, with formal powers varying by actor. Even this relatively clear example of multistakeholder governance has been subject to criticisms ranging from insufficient civil society participation; insufficient government authority; too much government oversight; too much American authority; questions about legitimacy; and longstanding and still ongoing concerns about its contractual relationship with the US government.

\section{The IETF and internet standard setting}

The IETF also has considerable coordinating influence over the Internet. It has developed many core Internet technical standards - such as the TCP/IP protocols - that serve as the rules enabling computing devices to exchange information over the Internet. Without these common specifications, devices made by one manufacturer would not be interoperable with other manufacturers' devices.

The IETF is one of many institutions that collectively create the blueprints enabling the Internet to have common addressing, compression standards, encryption standards, security standards, error detection and correction, formatting, and other key engineering features. Another standards organization, the W3C, has established most core standards specific to the web (e.g. HTML, XML). While these organizations perform highly technical functions, they also enact public policy in a variety of ways. For example, the strength and features of encryption standards mediate between conflicting values of law enforcement and privacy. Web accessibility standards 
determine the extent of online accessibility for the disabled. Economically, common standards provide a level playing field for competition and have contributed greatly to the network effects and growth of the Internet. ${ }^{24}$

The IETF is, in many ways, more open, but less formally multistakeholder than ICANN. The organization does not have an official or defined membership. Anyone is permitted to participate in standards development, either via online mailing lists or in person at one of several yearly gatherings. Those participating do so in their individual capacities rather than on behalf of institutions but, in practice, are usually associated with an employer, especially large technology companies that inherently develop, implement and depend upon Internet standards in their products (Internet Engineering Task Force 2004). Others work for governments or, less frequently, for civil society institutions such as universities and NGOs. Despite the institutional norm of participants acting in their personal capacity, we include it as a type of multistakeholder governance because many of the IETF's participants do in fact have other institutional affiliations with governments, NGOs and of course with corporations. Whereas IETF members participate in their individual capacities despite often having institutional affiliations, membership in the W3C is typically held by organizations - including companies, NGOs and units of governments, such as the Australian Government Information Management Office. Each member has one Advisory Committee Representative.

While this type of participatory openness is inclusive, meaningful participation requires specialized technical knowledge, the ability to speak English, funds to travel to international gatherings, and cultural competence in the stylistic and procedural norms of the organization. To this extent, even a completely participatory multistakeholder organization can have barriers related to knowledge, language, money, and culture.

The IETF is also unusually open and transparent regarding its deliberative process, informational documents, and standards. The entire history of its meeting proceedings is available online, as are most mailing list archives. The IETF has published the actual standards and supporting materials in an archive known as the Request for Comments (RFC) series. ${ }^{25}$

The IETF (and also the W3C), can most accurately be classified as homogeneous polyarchies. The IETF has no formal voting but, rather, makes decisions based on what has been called 'rough consensus and running code'. ${ }^{26}$

${ }^{24}$ On the policy implications of standards, see Palfrey and Gasser (2012).

25 All of the Internet RFCs are freely accessible on the IETF website, available at www.ietf.org.

${ }^{26}$ A term deriving from David Clark's plenary presentation, 'A Cloudy Crystal Ball, Visions of the Future,' at the 24th IETF in Cambridge, MA, July 1992. 'Proceedings of the 24th Internet Engineering Task Force,' p. 539. 
Both the IETF and the W3C adopt proposed standards according to public commentary processes that are open to participation. Although particular individuals may wield greater or lesser influence in practice (typically according to technical expertise and/or reputation), this influence does not stem from procedural rules vesting authority in a particular office-holder.

\section{The ITU and international telecommunications regulation}

The ITU is a United Nations specialized agency with global coordinating responsibility for information and communication technology areas such as radio spectrum allocation, coordination of satellite orbital positions, telecommunications standards, and the promotion of information and communication infrastructure advancements in the developing world. Originally called the International Telegraph Union, the organization was founded in 1865 to arrange for global telegraph standards.

As Internet data travels over a range of communication media, regulations set out by the ITU can influence most network operators. For example, it plays a facilitating role in the development of mobile communications networks that are increasingly important to Internet connectivity, especially in the developing world where wireless penetration is surpassing fixed broadband. The ITU also administers the International Telecommunication Regulations (ITRs), a treaty comprising binding rules of international law.

As described earlier, there is also a long history of tensions between the US government's unique coordinating oversight of the Internet's names and numbers (e.g. contract with ICANN, oversight of root zone file changes) and international calls for moving this oversight function, as well as other areas of Internet governance, to the ITU. The impasse has become a historic legitimacy contest. ${ }^{27}$ Many governments have requested a diminishment of the US Commerce Department's authority over the root, both symbolic and actual, and American interests have pushed back against the prospect of replacing this coordinating function with ITU oversight. For example, a 2012 United States House of Representatives hearing on 'International Proposals to Regulate the Internet' addressed concerns about a possible takeover of multistakeholder Internet governance by the United Nations ITU (International Proposals to Regulate the Internet 2012). The expressed position of the United States government is to preserve the fundamental multistakeholder model of governance. The United Nations, the ITU, and dominant multinational Internet companies have all espoused similar valorizations of multistakeholderism. These discourses around

27 On legitimacy contests, see Bukovansky (2002). 
'multistakeholderism' reflect longstanding international tensions about administrative control of the Internet and they all fail to define what is acceptable 'multistakeholder' governance for any particular function.

The ITU most centrally involves the representatives of governments (member states) but also includes international organizations, firms, NGOs, and academic institutions that can pay an annual membership fee to become 'sector members' and associates. Sector members, qua sector members, are not entitled to participate in the alteration either of the Constitution and Convention of the ITU, or of the treaties it oversees pertaining to radio communication or international telecommunications. These capacities are reserved to the ITU's 193 member states. Individual states may, and many routinely do, consult their sector members - even including them in treaty negotiation delegations - but such consultations are at the discretion of the state, which is equally free to consult interested parties that are not sector members. Sector members are able to participate more fully in the day-to-day standards-related work of the ITU. They receive access to the statistics and studies produced by the ITU in its information-gathering capacity; and they participate in its ongoing Study Groups. However, in a range of cases, Study Group recommendations must ultimately be approved by member states.

While we recognize that aspects of the ITU standard-setting process may approximate heterogeneous polyarchy, we nevertheless categorize the ITU as primarily hierarchical and thus not a case of multistakeholderism. ${ }^{28}$ It reserves important rule-making functions solely to one class of stakeholder. Further, while ITU sector membership is open to international organizations, firms and academic institutions, it is not open to NGOs or other civil society actors. This differentiates it from many, though not all, other instances of multistakeholderism.

\section{IOSCO}

The IOSCO establishes and promotes adherence to global standards for securities. It claims to regulate $95 \%$ of the securities markets around the world with the core objectives of protecting investors; maintaining fair, efficient, and transparent markets; and decreasing systemic risks in global securities markets (IOSCO 2010, 3). IOSCO is primarily an example of heterogeneous polyarchy, but it is also a somewhat ambiguous case that includes elements of homogeneous polyarchy.

IOSCO's 198 members include three actor classes: states, IGOs, and collections of firms. The organization recognizes three classes of

28 This characterization is consistent with Büthe and Mattli $(2011,34)$. They classify the ITU as a non-market public institution. 
membership - ordinary, associate, and affiliate members. Ordinary members (the largest group) include national securities commissions such as the SEC in the United States and the Financial Services Agency in Japan. Associate members are government agencies (other than principal securities regulators) or IGOs such as the World Bank and International Monetary Fund that have a relevant oversight function. Affiliate members include 'self-regulatory organizations, stock exchanges, financial market infrastructures, investor protection funds and compensation funds, and other bodies with an appropriate interest in securities regulation'. ${ }^{29}$ These classes of membership instantiate heterogeneous polyarchy, by differentially empowering actors to attend meetings, provide oral and written contributions to deliberations, and to vote. In keeping with the expectations of IR theory, state actors are generally privileged in these matters; however, IOSCO's practice of awarding membership to specific securities regulation agencies complicates the typical treatment of the state as a unitary actor. This provides some basis to think that it might be analytically productive to disaggregate the state as a class of actor in multistakeholder governance, along the lines suggested by analysts who emphasize intergovernmental networks.

IOSCO is also notable in that self-regulatory organizations can become full voting members if they are the primary securities regulator for a particular jurisdiction. The potential inclusion of private, self-regulatory associations as voting members makes IOSCO a rare instance of multistakeholderism that contemplates formal procedural equality between state and private actors. ${ }^{30}$ In such cases, the private actor would have a procedurally superordinate position to state agencies and IGOs in the associate member category as well as to other private actors in the affiliate member category. This complicates our treatment of polyarchy, in that authority relations do not break down neatly according to class of actor; a private ordinary member would have a formally equal position to some state agencies, a superordinate position with respect to others, and would also have a superordinate position with respect to other private actors. This illustrates the growing complexity of authority relations in contemporary global governance and suggests that the typology we present may eventually need to be extended in light of human creativity. Nevertheless, we believe that it remains generally reflective of current patterns of authority relations and that it represents an advance over previous binary treatments of authority in IR theory.

29 See IOSCO fact sheet, http://www.iosco.org/about/pdf/IOSCO-Fact-Sheet.pdf.

${ }^{30}$ For information on IOSCO membership rules (see http://www.iosco.org/about/index.cfm? section=membership). On private international law-making in IOSCO, see Bradley (2005). 


\section{The United Nations Global Compact}

The United Nations GC is an initiative promoting corporate citizenship and socially responsible business practices in areas such as the promotion of human rights, environmental protection, and the elimination of corruption. Launched by former UN Secretary-General Kofi Annan in 2000, it is a voluntary partnership between the UN and the private sector, with involvement of hundreds of NGOs as equal partners. The core of the GC is a set of principles drawn from international instruments including the Universal Declaration of Human Rights, the Fundamental Principles and Rights at Work, and the Rio Declaration on Environment and Development. Participating firms are asked to: 'advocate the GC in mission statements, annual reports, and similar public venues' to 'raise the level of attention paid to, and the responsibility for, these concerns within firms'. They are also asked to contribute reports documenting their efforts to translate the core GC principles into concrete action, as part of learning networks. Finally, they are asked to join UN 'partnership projects to benefit developing countries' (Ruggie 2001, 371-72).

An important caveat is that the principles of corporate citizenship adopted by the GC do not have any binding authority, regulatory teeth or enforcement mechanism. Instead, the GC relies on market mechanisms, more direct forms of public pressure by civil society groups and on the force of legitimate international norms to generate pressure for compliance. However, like the example of voluntary technical standards above, it can be loosely categorized as an example of 'governance' to the extent that it can contribute to norm setting and can influence and constrain private action in a number of public interest areas. Ruggie has argued that the GC is an interorganizational network (Ruggie 2001,375), and that it constitutes an example of 'new governance' wherein international organizations take what Abbott and Snidal have called a facilitative orchestration role (Abbott and Snidal 2009a, 558-75; Ruggie 2014, 10-11). Accordingly, we believe it is also consistent with the working definition of governance we adopted above: 'the coordinated, polycentric management of issues purposefully directed toward particular outcomes' (Welch 2013, 257).

The GC involves IGOs, states, firms and NGOs. While it primarily entails firms committing to principles of corporate social responsibility, it also entails important roles for states, international organizations and civil society. States established the GC via a UN General Assembly Resolution and provided voluntary funding, as well as diplomatic support (Ruggie 2004, 514). Firms' commitments are supplemented by the work of over 100 local networks that conduct 'learning exchanges, information sharing, working groups' and 'partnerships and dialogues that tackle issues specific 
to local contexts'. The UN reports that these networks include 'continued engagement by a diverse group of stakeholders, including academic institutions, business enterprises, NGOs and government entities' (United Nations Global Compact Office 2012, 6). The GC Board is 'a multi-stakeholder advisory body that meets annually... to provide ongoing strategic and policy advice for the initiative as a whole and make recommendations to the GC Office, participants and other stakeholders'. It 'is comprised of four constituency groups - business, civil society, labour and the United Nations with differentiated roles and responsibilities apart from their overall advisory function'. ${ }^{31}$ Thus, the GC has explicitly adopted the language of multistakeholder governance, and it has instantiated the concept in a heterogeneously polyarchic way, with differentiation of roles and responsibilities. While expressions of authority relations recede as a result of the relatively egalitarian distribution of authority among participants in the GC, again it is important to recognize that the equal distribution of authority is not the same as its absence. The principles underlying the GC and the more specific rules that outline conduct expected from participants are authoritative to the degree that participants accept them as legitimate. These rules differentially empower and constrain various actors, for example constraining firms to meet their commitments; and constraining the UN, states and civil society groups from branding compliant firms as bad actors, while empowering them to criticize participating actors found to violate their commitments as well as actors that refuse to participate.

\section{Variation in multistakeholder forms: authority relations and procedural rules}

Claims about multistakeholder governance clearly permeate several areas of global concern such as environmental protection, human rights, Internet governance, and finance. For scholars and practitioners of Internet governance, the issue area in which this concept is most fully and consistently articulated, this study is valuable in that it calls into question the article of faith that the Internet is governed in a unique, multistakeholder manner increasingly threatened by the encroachment of sovereign states. Multistakeholder governance is identifiable in other issue areas such as financial governance and corporate social responsibility. Equally, some important Internet governance functions are performed in ways that are clearly not instances of multistakeholderism, such as the policymaking role of information intermediaries in establishing practices for dealing with public

31 http://www.unglobalcompact.org/AboutTheGC/stages_of_development.html. 
Multistakeholderism: anatomy of an inchoate global institution 603

Table 3. Classification of cases

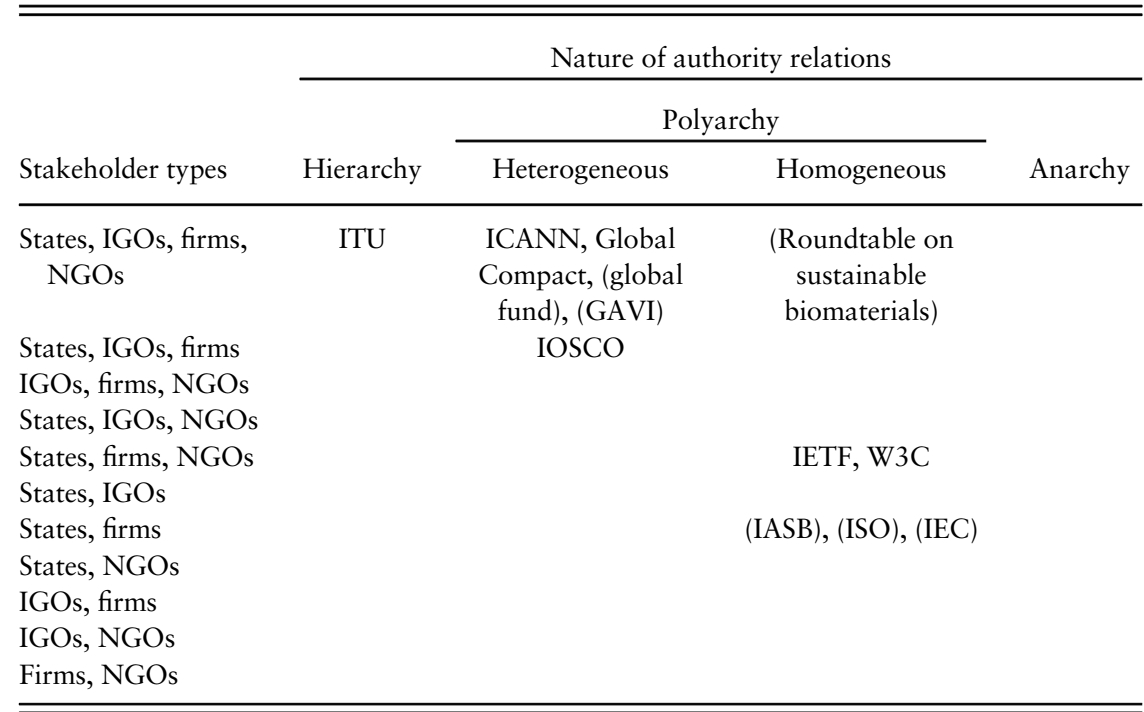

IGO = intergovernmental organizations; $\mathrm{NGO}=$ non-governmental organization; ITU = International Telecommunication Union; ICANN = Internet Corporation for Assigned Names and Numbers; IOSCO = International Organization of Securities Commissions; IETF = Internet Engineering Task Force; W3C = World Wide Web Consortium; IASB = International Accounting Standards Board; ISO = International Organization for Standardization; IEC = International Electrotechnical Commission.

interest areas such cyberbullying or establishing policies that directly determine the extent of user privacy online. Perhaps the most striking conclusion of our work for the study and practice of Internet governance is to call into question the extent to which Internet governance actually lives up to the talk about multistakeholderism. Across a number of crucial governance functions, the reality is perhaps closer to industry self-regulation than to genuine multistakeholder governance.

Of the five selected cases of institutions and initiatives that do involve multistakeholder coordination, there is variation in both types of actors and the authority relations among these actors. Table 3 summarizes this variation by classifying each case example into the schema of 22 forms of multistakeholder governance indicated in the Table 1 taxonomy presented earlier.

ICANN and the IETF both involve multiple types of stakeholders and both adopt authority relations distributed across these actors. In the case of ICANN, these authority relations are heterogeneous in the sense that formal powers vary by actor. Participation rights and decision-making 
powers in the IETF (and W3C) are more homogenously distributed among participants. The ITU, in contrast, is primarily hierarchical. Even though many classes of actors can weigh in as sector members, only member states are permitted to vote on ITRs or on the organization's constitutive instrument, and member states must also approve some recommendations emerging from multistakeholder Study Groups. In the area of financial regulation, IOSCO is primarily an example of heterogeneous polyarchy (albeit with elements of homogenous polyarchy) with influence distributed among states, IGOs and firms in their capacity as participants in industry self-regulatory collectives. The UN GC differentiates roles heterogeneously among all four actor classes - states, IGOs, firms, and NGOs - but does so in the least hierarchical fashion among the three cases of heterogeneous polyarchy examined.

The five cases examined in this article provide a small window into the variation in types of multistakeholder governance; however, they do not exhaust the list of cases. In order to facilitate future scholarly work along these lines, we briefly survey additional instances of multistakeholderism that have been speculatively positioned in Table 3 using parentheses. We also discuss gaps in the empirical illustration of the typology. Finally, we turn to the implications of the findings of our cases.

First, while we have treated two specific Internet governance cases in this paper as individual instances of multistakeholderism, another possibility would be to treat the entirety of what practitioners routinely call 'the Internet governance ecosystem' as a single, macro-level case of multistakeholderism. We opted not to take this approach, in order to point out meaningful variation in the way multistakeholderism is instantiated within this issue area, and also to point out that much of Internet governance (including one of our cases) is decidedly not multistakeholder. We prefer Nye's approach drawing on the regime complex literature, but feel it important to point out this alternate perspective.

Büthe and Mattli characterize the International Organization for Standardization (ISO), the International Electrotechnical Commission (IEC) and the International Accounting Standards Board as private non-market standard-setting bodies. However, we believe that this characterization overlooks the degree to which these bodies include a variety of types of actors. For example, the ISO is an international network comprising national standards bodies. Some of these bodies are government agencies or armslength quasi-govermental entities, while others are non-profit entities often with close ties to manufacturing firms. While we believe that ISO and IEC are therefore instances of multistakeholderism, we accept the Büthe and Mattli characterization of their activities as 'centrally coordinated global networks comprising hundreds of technical committees' as well as their finding that 
these organizations are fundamentally political (Büthe and Mattli 2011, 5). Given the restriction of membership in these bodies to national standards bodies and the formally horizontal procedures for standard setting within them, we tentatively classify these three organizations as cases of homogeneous polyarchy including states and firms. Furthermore, we believe that their focus on the politics of global rule-making is compatible with the approach taken here.

Kenneth W. Abbott and David Gartner found that 'recent global health institutions have embraced a multi-stakeholder model in which nongovernmental organizations (NGOs), the private sector, private foundations, and other constituencies within civil society - including populations directly affected by health threats - participate directly in governance structures, deliberation, and decision-making' (Abbott and Gartner 2012, 4). They identify the Global Fund to fight AIDS, Tuberculosis and Malaria (Global Fund) as one prominent example, alongside GAVI. Both GAVI and the Global Fund are broadly multistakeholder, including all four of the classes of actors we identify. Both also have complex governance structures that distribute roles and responsibilities differentially (see, The Global Fund 2014; GAVI 2015). Accordingly, we suggest they are best seen as instances of heterogeneous polyarchy.

Finally, the Roundtable on Sustainable Biomaterials (RSB) is an instance of relatively homogeneous polyarchy including states, IGOs, firms and civil society actors. ${ }^{32}$ Members of the RSB are divided by actor class into seven 'Chambers' (three comprised of firms; three comprised of various kinds of civil society organizations; and one combining government, IGOs and academics). Each Chamber has equal weight in constituting the RSB's main governing body, the Assembly of Delegates. The Assembly of Delegates votes on modifications to the organization's core standards and appoints the RSB Board to run daily operations (Roundtable on Sustainable Biomaterials 2015). While voting shares are not equally allotted to different actor classes, the RSB does not distinguish classes of membership, or endow different actor classes with distinctive powers and responsibilities.

One important cluster of cases not addressed here cuts across a wide variety of issue areas: those involving states and IGOs. These are among the most familiar cases to students of IR, and can be reasonably expected to number among the most common types in practice, but they are not typically thought of as cases of multistakeholder governance. Recent scholarship has studied these relationships in terms of principal-agent theory (see, e.g., Hawkins et al. 2006). However, insofar as these agents

32 The authors thank an anonymous reviewer for alerting them to the existence of the RSB. 
exhibit de facto independence from their principals, it may be more productive to approach some such cases as instances of multistakeholder governance. Doing so places additional emphasis on the agency of at least some IGOs, and might permit more complete understanding of those that are highly autonomous in at least some areas of their work. Candidates for such treatment would include the European Union, as well as dispute resolution procedures in the World Trade Organization. At a minimum, there are parallels between multistakeholder governance and highly delegated principal-agent relationships that should be explored in greater depth; it may be that these relationships are best thought of in terms of a spectrum.

Shifting from examination of state-IGO relations in terms of principals delegating to agents to an understanding of these relations in terms of multistakeholder governance also seems promising to us in light of the increasing role of civil society actors. Major IGOs increasingly face demands from civil society groups of various kinds, including NGOs and indigenous peoples' movements, as well as from firms. These non-state actors cannot formally delegate to IGOs by virtue of the structure of their constitutive instruments, but they increasingly factor into the decisions IGOs make about how to implement programs and fulfill their missions. This influence is difficult to explain as a function of the power resources possessed by these non-state actors, especially relative to those possessed by states. A better explanation might be that IGO secretariats increasingly accept as appropriate the notion that such non-state actors' concerns should be taken into account. Put another way, the secretariats increasingly accept that these non-state actors are entitled to participate as stakeholders in governance, albeit not typically in precisely the same ways as other classes of actors. Developing conceptual tools that more easily accommodate such emerging patterns may prove useful.

The range of cases involving states and firms is also not well covered by our empirical illustrations in this article. These include various kinds of regulatory mechanisms where private firms, and associations of firms, play governance roles with varying degrees of oversight from and interaction with state agencies, ${ }^{33}$ as well as the standard-setting cases covered by Büthe and Mattli. While such privatization of governance has occurred in a range of industry sectors, it has perhaps been most consequential in the global financial system, where it arguably compromised the effectiveness and legitimacy of the system and involved a high degree of regulatory capture. ${ }^{34}$

33 On industry participation in regulation, see Haufler (2001).

34 On the involvement of private firms and associations of firms in global financial governance, see also: Underhill and Zhang (2008); Baker (2010); Helleiner et al. (2010). 
Taken together, the cases suggest that even using a limited set of examples, there is clearly variation among different instances of multistakeholder governance. Much of this variation is produced by the procedural rules constituting particular governance institutions, mechanisms and processes. These rules govern eligibility for various kinds of membership and the distribution of various decision-making capacities among members (including voting rules). They also establish standards for evaluating and responding to proposals, interpretations and arguments presented by other actors (Raymond 2011). They therefore simultaneously empower and constrain actors, to the point of determining whether and how they are entitled to participate in a particular governance process.

The nature of authority relations between actors in a given social context is thus a product of these procedural rules. Classifying a particular governance institution or organization as hierarchic or (homogeneously or heterogeneously) polyarchic is a matter of inductively identifying procedural rules. Further, two institutions or organizations that fall into the same broad classificatory category may also employ slightly different procedural rules that share family resemblances; and the same institution or organization may undergo change in its procedural rules over time, which may or may not require that it be reclassified in the schema proposed above. Finally, this means that if an attempt is to be made to make an institution more or less multistakeholder in nature, or if an attempt is to be made to change the form of multistakeholderism employed in a particular organization, accomplishing such goals requires changes to its procedural rules. These changes must be such that different classes or combinations of classes of actors will be relatively enabled and constrained in exercising control over the institution or organization in question.

An understanding of the connections between procedural rules, authority relations, and variations in forms of multistakeholder governance is important at least in part because in the absence of mutually agreed-upon procedural rules for rule-making, interpretation and application, the creation of new governance mechanisms is unlikely. Discussions and negotiations are likely to founder on procedural grounds. Disagreement over procedural rules complicates not only the creation of new governance mechanisms, but also the operation of existing ones. This is because the social reproduction of these rules, institutions and processes occurs through the continued application of general rules to particular cases, which in turn depends on mutually accepted procedures for rule-making, interpretation and application. Legitimate procedural rule-sets are therefore crucial to the continued operation of the extensive system of global governance that characterizes contemporary world politics. The increasing demands for increased participation (and new forms of participation) being articulated 
by emerging powers and by non-state actors are inconsistent both with each other and with pre-existing international rule-making procedures. Accordingly, the potential for increased friction is considerable and likely to grow. ${ }^{35}$

Such disagreements on legitimate procedures for rule-making are evident in the Internet governance issue area; at least five partially overlapping sets of procedural rules are identifiable. The first might usefully be called an OECD view, since it is held primarily by member states of the OECD. It consists of commitment to the rule of law (domestically and internationally), even to the point of considering a conditional view of sovereignty, along with acceptance of multilateral cooperation among states and the relatively routine consultation of stakeholders. This consultation of stakeholders has begun, primarily over the past 20 years, to take the form of increased reliance on industry self-regulation not only in the Internet field but also in financial governance of various kinds and other areas involving technical standard setting. Within the information governance area broadly conceived, this procedural approach to rule-making is evident in the 1988 ITRs treaty and in the World Intellectual Property Organization.

The second set of procedural rules can be summarized as the Shanghai Cooperation Organization (SCO) view. It emphasizes great power privilege in the operation of the international system and entails a strong rather than conditional interpretation of sovereignty. It is based on hierarchical statesociety relations and limited or non-existent stakeholder consultation. This view is held primarily by China and Russia, but bears some similarities to the procedural views of the remaining BRICS. As this approach to rulemaking is held by states that have lacked dominant influence both over the Internet and over world politics since the Internet's commercialization, institutionalized examples of such procedures are difficult to identify within the Internet governance issue area. These views, however, inform the opposition of these states to legacy mechanisms of Internet governance given their connections to the United States; they also inform suspicion of, and opposition to, the multistakeholder model.

The third set of procedural rules is held by the primarily post-colonial members of the G-77. While this is the most diverse of the five sets of procedural rules, some commonalities can be identified. First, like the SCO view, the G-77 view of procedural legitimacy emphasizes a robust conception of sovereignty. This insistence on sovereignty stems at least in part from the challenges faced by weak states emerging from colonization

${ }^{35}$ For a similar argument in the context of contemporary international law, see Raymond (2013a). 
(Jackson 1990). In addition, these states struggle to varying extents with issues of expertise and capacity; these inequalities have contributed to preferences that privilege existing multilateral institutions with which states have extensive experience over innovative forms of international and multistakeholder cooperation. The preference among many developing world states for a broader ITU role in Internet governance, is an example of this preference for existing multilateral institutions with voting rules based on sovereign equality.

The first three sets of procedural rules are endemic to IR, but the fourth and fifth are not. The epistemic community of technologists has a distinct view of how to legitimately make and interpret rules, which is perhaps best exemplified by the IETF's RFC process. In this process, 'the basic ground rules were that anyone could say anything and that nothing was official, ${ }^{36}$ The IETF mission statement continues to reflect this ethos, with its affirmation of the organization's commitment to 'rough consensus and running code' (Internet Engineering Task Force 2004). Though individual bodies have their own processes, the Internet technical community tends to adopt horizontal, distributed and voluntaristic rule-making procedures reflective of its members' values.

Fifth, and finally, corporate stakeholders that have driven the development of the commercial Internet also have distinct views on rule-making and interpretation. These views are rooted in voting by corporate boards subject to shareholder accountability, hierarchical chains of accountability within the firm, and external relationships based on private contracts. Though some technology companies make conscious efforts to embody the spirit of the technical community, norms of corporate governance also affect their behavior; this is especially true of companies that pursue public stock offerings. ICANN's contractual model of delegating to RIRs and to generic gTLD registries is one example of Internet governance done on the basis of corporate procedural rules; interconnection between network operators is another.

The increasing importance of the Internet to everyday life has begun to generate new entrants into the governance process. Corporate actors were the first non-technical players, but the current trend is increased interest on the part of both industrial and non-industrial states. The Internet's growing integration with a range of public and private activities is also creating new interests and making additional social values salient for existing governance participants. Resolving the attendant conflicts and tradeoffs is complicated

\footnotetext{
${ }^{36}$ For information on the history of the Request for Comments process, see Reynolds and Postel (1987).
} 
by the diversity of views on appropriate procedures for making, interpreting and applying rules. Without a procedural modus vivendi, it is unlikely that distributional questions will be effectively addressed. ${ }^{37}$

\section{Conclusion}

This paper has attempted to provide a more nuanced study of multistakeholder governance as a class of phenomena across multiple issue areas, albeit with particular attention to Internet governance issues. Multistakeholderism is not a single approach to governance and multistakeholder forms of multistakeholder governance are not unique to, or even always applicable to, how the Internet is run. In this concluding section of this paper, we summarize the potential gains of these insights, indicate areas for further research, and offer some caveats about multistakeholderism.

'Multistakeholderism' is sometimes viewed as a value in itself rather than a possible set of approaches for meeting more salient public interest objectives such as human rights, Internet security and performance or financial stability. The more appropriate approach to responsible and efficacious governance requires determining what types of administration are optimal in any particular functional and political context. For example, in the area of Internet governance, some policymaking tasks may appropriately be relegated to the private sector, some the purview of traditional sovereign state governance or international treaty negotiations, and some more appropriately multistakeholder. Determining which mode of governance is appropriate for various global administrative functions may require conceptual and theoretical tools that have not yet been developed. The study of multistakeholderism as an institutional form presented in this article provides a foundation on which they can be built.

The practical value of this approach is evident in the Internet governance case. Our argument highlights a set of more prescriptive questions that are impossible without nuanced conceptions of Internet governance and of multistakeholderism like the ones we present here. One such question is whether there is a need for more multistakeholderism in particular functional areas of Internet governance, or whether there are more effective and more appropriate means of instantiating democratic values in areas of policy likely to engage important public values and interests. Another question made possible by a more sophisticated conceptual framework is whether particular governance functions are matched with appropriate

\footnotetext{
${ }^{37}$ IRs theory has, with a small number of exceptions, taken insufficient notice of the empirical importance of justice considerations (whether procedural or distributive) in explaining outcomes. On these questions, see: Welch (1993); Albin (2001).
} 
forms of multistakeholder governance - or, more fundamentally, whether particular functions are better accomplished through means other than multistakeholderism. Finally, to what extent is the concept of multistakeholderism deployed as a proxy for broader political struggles or as an impediment to the types of coordination necessary to promote conditions of responsible governance? For example, governments can advocate for topdown and formalized multistakeholderism to gain additional power in areas in which they have traditionally not had jurisdiction. Alternatively, companies and other actors with vested interests in current governance arrangements can deploy multistakeholderism in a manner either meant to exclude new entrants (whether public or private) with incommensurate interests and values or to preserve incumbent market advantage.

Definitively answering such questions requires a great deal of further research on the connections between issue characteristics and the properties of rule sets and organizations, on the one hand, and the effectiveness and legitimacy of governance on the other hand. It is especially important to adopt a broad comparative strategy that looks for insights from other related areas. Given the global nature of the Internet, literatures in IR and global governance are promising sources. However, scholars in these fields remain in the early stages both of understanding issues of institutional performance and design, ${ }^{38}$ and studying forms of governance where the state is (at least under some conditions) merely one actor among many.

In addition, the comparative study of multistakeholder governance as a class of phenomena offers substantial benefits to scholars of IR and global governance. First, it provides additional cases in which to study the role of private actors in governance. Second, it offers the potential to extend understanding of what kinds of institutions perform most effectively and enjoy greater legitimacy in dealing with novel, complex, technical and transnational issues of increasing political salience. It does so by extending the types of institutions studied in the literatures on institutional effectiveness and design. Third, it furnishes additional evidence of the presence and complexity of authority relations in international politics. It demonstrates the existence of authority relations in world politics in which the state is either absent or is embroiled in heterogeneously polyarchic relations with non-state actors of various kinds. At a more general level, the comparative study of multistakeholder governance demonstrates the inadequacy of conceiving authority as binary and of understanding authority as a properly solely of actors and not also of rules.

\footnotetext{
${ }^{38}$ For one notable effort, see Koremenos et al. (2001). See also the other articles in this special issue, including the critical piece by Wendt (2001).
} 
Finally, the argument presented here is relevant both to scholars of Internet governance and of IR because it demonstrates the importance of procedural rules. Specifically, it clearly connects them to the study both of institutional forms and of authority in world politics. Such rules are critical to producing variation in institutional and organizational forms, both among and within the types elaborated in this paper, as well as between multistakeholder and non-multistakeholder forms of governance. As such, procedural rules are also of vital practical importance; institutions and organizations that depend on illegitimate procedures are unlikely to enjoy broad acceptance (and thus effectiveness). Further, the fact that major actors in Internet governance endorse diverse views of procedural legitimacy helps explain the rising tension in this issue area and also suggests that actors should attempt to forge a procedural modus vivendi prior to attempting to resolve substantive issues.

\section{Acknowledgments}

The authors thank the Centre for International Governance Innovation for its support of this research. They also thank Samantha Bradshaw for her research assistance. An earlier version of this paper was presented at the 8th Annual GigaNet Symposium, Bali, Indonesia, 21 October 2013; the authors thank the participants for their helpful comments. Finally, the authors thank the anonymous reviewers and the journal's editorial team for their invaluable suggestions. Any remaining errors are, of course, our own.

\section{References}

Abbott, Kenneth W., and David Gartner. 2012. "Reimagining Participation in International Institutions." Journal of International Law and International Relations 8:1-35.

Abbott, Kenneth W., and Duncan Snidal. 2000. "Hard and Soft Law in International Governance." International Organization 54(3):421-56.

_ 2009a. "Strengthening International Regulation Through Transnational New Governance: Overcoming the Orchestration Deficit." Vanderbilt Journal of Transnational Law 42:501-78.

— 2009b. "The Governance Triangle: Regulatory Standards Institutions and the Shadow of the State." In The Politics of Global Regulation, edited by Walter Mattli, and Ngaire Woods, 44-88. Princeton: Princeton University Press.

Abbott, Kenneth, Robert O. Keohane, Andrew Moravcsik, Anne-Marie Slaughter, and Duncan Snidal. 2000. "The Concept of Legalization.” International Organization 54(3):401-19.

Albin, Cecilia. 2001. Justice and Fairness in International Negotiation. Cambridge: Cambridge University Press.

Antonova, Slavka. 2008. Powerscape of Internet Governance - How was Global Multistakeholderism Invented in ICANN? Saarbrücken, Germany: VDM Verlag.

Baker, Andrew. 2010. "Restraining Regulatory Capture? Anglo-America, Crisis Politics and Trajectories of Change in Global Financial Governance." International Affairs 86(3):647-63. 
Balkin, Jack M. 2008. “The Future of Free Expression in a Digital Age.” Pepperdine Law Review 36:427-44. http://ssrn.com/abstract=1335055.

Barlow, John P. 1996. “A Declaration of the Independence of Cyberspace.” Davos, Switzerland, February 8. Accessed November 14, 2014. https://projects.eff.org/ barlow/DeclarationFinal.html.

Bradley, Caroline. 2005. "Private International Law-Making for the Financial Markets." Fordham International Law Journal 29(1):127-80.

Brousseau, Eric, Meryem Marzouki, and Cécile Méadel. eds. 2012. Governance, Regulation, and Powers on the Internet. Cambridge: Cambridge University Press.

Bukovansky, Mlada. 2002. Legitimacy and Power Politics: The American and French Revolutions in International Political Culture. Princeton: Princeton University Press.

Bull, Hedley. 2002. The Anarchical Society: A Study of Order in World Politics, 3rd ed. New York: Columbia University Press.

Büthe, Tim, and Walter Mattli. 2011. The New Global Rulers: The Privatization of Regulation in the World Economy. Princeton: Princeton University Press.

Bygrave, Lee A., and Jon Bing. eds. 2009. Internet Governance: Infrastructure and Institutions. Oxford: Oxford University Press.

Cerf, Vint, Patrick Ryan, and Max Senges. 2014. "Internet Governance is Our Shared Responsibility." I/S: A Journal of Law and Policy 10(1):1-41.

Dahl, Robert A. 1956. A Preface to Democratic Theory. Chicago: University of Chicago Press. 1972. Polyarchy: Participation and Opposition. New Haven: Yale University Press.

DeNardis, Laura. 2014. The Global War for Internet Governance. New Haven: Yale University Press.

Drezner, Daniel W. 2000. "Bargaining, Enforcement, and Multilateral Sanctions: When is Cooperation Counterproductive?” International Organization 54(1):73-102.

Dutton, William H., John Palfrey, and Malcolm Peltu. 2007. "Deciphering the Codes of Internet Governance: Understanding the Hard Issues at Stake." Forum Discussion Paper No. 8, Oxford Internet Institute and e-Horizons Institute, January .

Dutton, William H., Anna Dopatka, Michael Hills, Ginette Law, and Victoria Nash. 2011. Freedom of Connection-Freedom of Expression: The Changing Legal and Regulatory Ecology Shaping the Internet. Paris: UNESCO. http://papers.ssrn.com/sol3/papers.cfm? abstract_id=1654464.

Epstein, Dmitry. 2013. "The Making of Institutions of Information Governance: The Case of the Internet Governance Forum.” Journal of Information Technology 28:137-49.

GAVI Alliance. 2015. “Governing GAVI.” Accessed November 14, 2014. http://www.gavi.org/ about/governance/.

Glasius, Marlies. 2010. Expertise in the Cause of Justice: Global Civil Society Influence on the Statute for an International Criminal Court. Oxford: Oxford University Press.

Haas, Peter M. 1992. "Introduction: Epistemic Communities and International Policy Coordination.” International Organization 46(1):1-35.

Haufler, Virginia. 2001. A Public Role for the Private Sector: Industry Self-Regulation in a Global Economy. Washington, DC: Carnegie Endowment for International Peace.

Hawkins, Darren G., David A. Lake, Daniel L. Nielson, and Michael J. Tierney. eds. 2006. Delegation and Agency in International Organizations. Cambridge: Cambridge University Press.

Helleiner, Eric, Stefano Pagliari, and Hubert Zimmermann. eds. 2010. Global Finance in Crisis: The Politics of International Regulatory Change. New York: Routledge.

Hobson, John M., and Jason C. Sharman. 2005. "The Enduring Place of Hierarchy in World Politics: Tracing the Social Logics of Hierarchy and Political Change.” European Journal of International Relations 11(1):63-98. 
Hurd, Ian. 1999. "Legitimacy and Authority in International Politics." International Organization 53(2):379-408.

Ikenberry, G. John. 2001. After Victory: Institutions, Strategic Restraint, and the Rebuilding of Order after Major Wars. Princeton: Princeton University Press.

International Proposals to Regulate the Internet. 2012. "Hearing Before the Committee on Energy and Commerce, House of Representatives." $112^{\text {th }}$ Congress, May 31, 2012, United States Government Printing Office, Washington, DC.

Internet Engineering Task Force. 2004. “A Mission Statement for the IETF.” RFC3935. Accessed November 14, 2014. http://www.ietf.org/rfc/rfc3935.txt.

IOSCO. 2010. "Objectives and Principles of Securities Regulations.” Accessed November 14, 2014. https://www.iosco.org/library/pubdocs/pdf/IOSCOPD323.pdf.

Jackson, Robert H. 1990. Quasi-States: Sovereignty, International Relations and the Third World. Cambridge: Cambridge University Press.

Keck, Margaret E., and Kathryn Sikkink. 1998. Activists Beyond Borders. Ithaca: Cornell University Press.

Keene, Edward. 2007. "A Case Study of the Construction of International Hierarchy: British Treaty-Making against the Slave Trade in the Early Nineteenth Century." International Organization 61(2):311-39.

_ 2013. "International Hierarchy and the Origins of the Modern Practice of Intervention." Review of International Studies 39(5):1077-90.

Keohane, Robert O. 1990. "Multilateralism: An Agenda for Research.” International Journal 45(4):731-64.

Koremenos, Barbara, Charles Lipson, and Duncan Snidal. 2001. "The Rational Design of International Institutions.” International Organization 55(4):761-99.

Krasner, Stephen D. 1991. "Global Communications and National Power: Life on the Pareto Frontier.” World Politics 43(3):336-66.

Krouse, Richard W. 1982. "Polyarchy and Participation: The Changing Democratic Theory of Robert Dahl.” Polity 14(3):441-63.

Lake, David A. 2007. "Escape from the State of Nature: Authority and Hierarchy in World Politics." International Security 32(1):47-79.

2009. "Regional Hierarchy: Authority and Local International Order." Review of International Studies 35(S1):35-58.

Malcolm, Jeremy. 2008. Multi-Stakeholder Governance and the Internet Governance Forum. Wembley, Australia: Terminus Press.

March, James G., and Johan P. Olsen. 1998. "The Institutional Dynamics of International Political Orders." International Organization 52(4):943-69.

Martin, Lisa L., and Beth A. Simmons. 1998. "Theories and Empirical Studies of International Institutions.” International Organization 52(4):729-57.

Mathiason, John. 2008. Internet Governance: The New Frontier of Global Institutions. New York: Routledge.

Mueller, Milton. 2010. Networks and States: The Global Politics of Internet Governance. Cambridge: MIT Press.

Mueller, Milton L. 2002. Ruling the Root: Internet Governance and the Taming of Cyberspace. Cambridge: MIT Press.

Mueller, Milton L., Andreas Schmidt, and Brenden Kuerbis. 2013. "Internet Security and Networked Governance in International Relations." International Studies Review 15(1): 86-104.

National Telecommunications and Information Administration (NTIA). 2014. "NTIA Announces Intent to Transition Key Internet Domain Name Functions.” Press release. 
Accessed March 14, 2014. www.ntia.doc.gov/press-release/2014/ntia-announces-intenttransition-key-internet-domain-name-functions.

Nye, Joseph S. Jr. 2014. “The Regime Complex for Managing Global Cyber Activities.” Global Commission on Internet Governance Paper Series, Paper No. 1. Accessed November 14, 2014. https://www.cigionline.org/publications/regime-complex-managing-global-cyberactivities.

Orsini, Amandine, Jean-Frédéric Morin, and Oran Young. 2013. "Regime Complexes: A Buzz, a Boom, or a Boost for Global Governance?” Global Governance 19(1):27-39.

Ostrom, Elinor. 2010. "Beyond Markets and States: Polycentric Governance of Complex Economic Systems." The American Economic Review 100(3):641-72.

Ostrom, Vincent, Charles M. Tiebout, and Robert Warren. 1961. "The Organization of Government in Metropolitan Areas: A Theoretical Inquiry." American Political Science Review 55(4):831-42.

Palfrey, John, and Urs Gasser. 2012. Interop: The Promise and Perils of Highly Interconnected Systems. New York: Basic Books.

Price, Richard. 1998. "Reversing the Gun Sights: Transnational Civil Society Targets Land Mines." International Organization 52(3):613-44.

Raymond, Mark. 2011. "Social Change in World Politics: Secondary Rules and Institutional Politics." PhD diss., University of Toronto.

2013a. "Renovating the Procedural Architecture of International Law." Canadian Foreign Policy Journal 19(3):268-87.

2013b. "Puncturing the Myth of the Internet as a Commons." Georgetown Journal of International Affairs. International Engagement on Cyber III (special issue): 5-16.

2015. "Locating Authority in the International System: Authoritative Rules and PostAnarchy International Relations Theory.” Paper presented at the International Studies Association Annual Conference, New Orleans, LA, February 21. http://web.isanet.org/Web/ Conferences/New\%20Orleans\%202015/Archive/2a4f40c4-2b9b-4e24-acc6-2ee07be7bacd. pdf.

Reus-Smit. 1997. "The Constitutional Structure of International Society and the Nature of Fundamental Institutions." International Organization 52(4):555-89.

- 1999. The Moral Purpose of the State: Culture, Social Identity and Institutional Rationality in International Relations. Princeton: Princeton University Press.

Reynolds, Joyce, and Jon Postel. 1987. "The Request for Comments Reference Guide." RFC1000. http://www.ietf.org/rfc/rfc1000.txt.

Rosenau, James N. 1995. "Governance in the Twenty-First Century." Global Governance $1(1): 13-43$.

Roundtable on Sustainable Biomaterials. 2015. "RSB Governance.” Accessed November 14, 2014. http://rsb.org/about/governance/.

Ruggie, John Gerard. 1992. "Multilateralism: The Anatomy of an Institution.” International Organization 46(3):561-98.

2001. "global_governance.net: The Global Compact as Learning Network." Global Governance 7(4):371-78.

2004. "Reconstituting the Global Public Domain - Issues, Actors, Practices." European Journal of International Relations 10(4):499-531.

_ 2014. "Global Governance and 'New Governance Theory': Lessons from Business and Human Rights.” Global Governance 20(1):5-17.

Sharman, Jason C. 2013. "International Hierarchies and Contemporary Imperial Governance: A Tale of Three Kingdoms." European Journal of International Relations 19(2): 189-207. 
Slaughter, Anne-Marie. 2004. A New World Order. Princeton: Princeton University Press. Stauffacher, Daniel, and Wolfgang Kleinwächter. 2005. The World Summit on the Information Society. New York: United Nations Information and Communication Technologies Task Force.

The Global Fund. 2014. “Governance Handbook.” Accessed November 14, 2014. http://www. theglobalfund.org/en/board/.

Underhill, Geoffrey R.D., and Xiaoke Zhang. 2008. "Setting the Rules: Private Power, Political Underpinnings, and Legitimacy in Global Monetary and Financial Governance.” International Affairs 84(3):535-54.

United Nations Global Compact Office. 2012. "Global Compact Local Network Report 2012.” New York, United Nations. Accessed November 14, 2014. http://unglobalcompact.org/ docs/publications/LN_Report_2012.pdf.

Waltz, Kenneth N. 1979. Theory of International Politics. Boston: McGraw-Hill.

Weiss, Thomas G., and Rorden Wilkinson. 2014. "Rethinking Global Governance: Complexity, Authority, Power, Change." International Studies Quarterly 58(1):207-15.

Weissbrodt, David, and Maria Kruger. 2003. "Norms on the Responsibilities of Transnational Corporations and Other Business Enterprises with Regard to Human Rights." American Journal of International Law 97(4):901-22.

Welch, David A. 1993. Justice and the Genesis of War. Cambridge: Cambridge University Press. 2013. "What is 'Governance,' Anyway?” Canadian Foreign Policy Journal 19(3):253-58.

Wendt, Alexander. 1998. "On Constitution and Causation in International Relations." Review of International Studies 24(5):101-18. 2001. "Driving with the Rearview Mirror.” International Organization 55(4):1019-49.

Wilkinson, Rorden. 2000. Multilateralism and the World Trade Organization. London: Routledge.

Working Group on Internet Governance (WGIG). 2005. "Report of the Working Group on Internet Governance.” Working Group on Internet Governance, Chateau de Bossey. Accessed May 15, 2014. http://www.wgig.org/docs/WGIGREPORT.pdf. 